The advent of cheap oxygen in bulk is bound to bring about revolutionary changes, particularly in metallurgy and gas-making. The boon to these industries in being able to employ what is virtually a nitrogen-free product is sufficiently apparent. Even before the War the use of enriched air for iron smelting attracted attention, and for several years the late Dr. Peters ran a small blast-furnace at Ougrée, Belgium, with slightly oxygenated air obtained by centrifuging atmospheric air on the principle so capably and patiently developed by the veteran engineer, Prof. Mazza, of Turin. The application of oxygen or enriched air to iron making will involve important changes in the chemical reactions involved and in the character of the furnace.

The advantages of oxygen treatment for pulmonary complaints has long been recognised; during the War, and afterwards, a mixture of oxygen and nitrous oxide has proved invaluable in anæsthesia. To render oxygen cheap and plentiful, and to reduce the still grievous weight of the cylinders in which it is carried, would, from the medical point of view, be a great blessing; moreover, in modern warfare it would be of incalculable service to both the military forces and the civil population.

\title{
The Transport of Food Substances in the Plant.
}

I $F$ the stem of a flowering plant is cut across, examination under the microscope reveals the constant presence of three striking tissue systems with their elements extended in a longitudinal direction through the stem, which lie embedded in ground tissue, the cells of which are much less elongated. The outermost of these tissues is composed of fibres in which the walls nearly fill up the cell cavity, and is regarded as strengthening in nature. Within this are two tissues : first, the phloem with elastic walls usually of cellulose, and innermost, the xylem with rigid lignified walls. To these tissues botanists have been practically unanimous in attributing different functions in relation to transport, the xylem being looked upon as carrying the ascending column of water, the phloem as bearing the downward current of manufactured food substances. When, however, Prof. H. H. Dixon, after a preliminary communication to NATURE of February 23, I922 (vol. rog, p. 236), challenged these longestablished views in his presidential address to Section $\mathrm{K}$ (Botany) at the British Association meeting at Hull in 1922 , it soon became clear upon what a relatively slender experimental basis they rested. The phloem being situated outside the xylem in the stem, it is possible, by cutting a shallow groove, to sever all communication through the phloem whilst leaving the xylem intact. When such ringing experiments are performed, an accumulation of food takes place above the ring, and on the basis of such experiments, largely developed and extended by F. Czapek, who showed that when the phloem was severed in the petiole, for example, starch fails to disappear from the leaf-blade above, the conclusion has been reached that the phloem must be responsible for the downward movement of food substances. Dixon directs attention to Deleano's earlier criticism of these experiments, and certainly, in view of the wider knowledge now available as to the complicated machinery involved in the disappearance of starch from a leaf-blade, many of these experiments cannot now be regarded as convincing, although the accumulation of food substances above a ring upon a leafy stem remains a very significant, well-known fact.

Dixon's main criticism of the view that the phloem is thus functional recalls the "Statical Essays" of the pioneer plant physiologist, Stephen Hales. Considering the carbohydrate present in a potato tuber, and the length of time in which a tuber forms, measuring the cross-section of the phloem in the underground stem leading to the tuber, he estimates the rate at which that carbohydrate must have moved as sugar along the phloem to the tuber. Assuming a sugar solution of Io per cent. concentration, he finds that its rate of flow would need to have been $50 \mathrm{~cm}$. per hour. Similar calculations, using available data on photo-synthesis in the leaf and measuring the cross-section of the phloem in the petiole, give velocities of the same order for a ro per cent. solution, figures being obtained of from $20 \mathrm{~cm}$. to $140 \mathrm{~cm}$. per hour. As Dixon points out, no such rate of flow has ever been contemplated by botanists, and the structure of the sieve tubes, the long elements in the phloem with pitted transverse plates, is by no means suited for the transmission of liquid in mass at this rate. It is true that the slimy contents of the sieve tube may contain a much more concentrated solution, Dixon's figure of $2 \cdot 5$ to 5 per cent. concentration in the xylem vessel scarcely being relevant, but such greater concentration would still leave an unexpectedly high rate of flow, for which the phloem seems utterly unfitted. Dixon's alternative explanation is that the bulk of the transport is carried out along the wider vessels of the xylem, in which a more dilute solution may move readily along a channel of greater cross-section.

Dixon marshals experimental evidence for an occasional downward flow in the xylem, from the early experiments of Stephen Hales, in which a tree was inarched into two adjacent trees, its roots being taken out of the ground and its supplies of water drawn entirely from the neighbouring trees. The possibility of such a downward flow will not be doubted ; Dixon's difficulty is to show that such a downward flow is of sufficiently regular occurrence in the normal plant to account for the constant return of assimilates from the leaf to the rest of the plant. In this connexion his reminder is timely that earlier experiments have shown how isolated neighbouring tracts of conducting tissue may be within the same stem, so that currents of sap in opposite directions in the xylem of a same shoot are conceivable; they have still, however, to be demonstrated. As a possible driving force for such occasional return currents of sap he directs attention to Thoday's observations upon the changes in volume of a leaf, which may amount to as much as 7 per cent. of the leaf volume in ten minutes. Obviously, however, there is as yet no evidence from the anatomical structure of the leaf to assume that such volume changes should compress liquid into the xylem vessels, and the only observations showing a return drive of sugar solution along the leaf petiole have been obtained by Pitra, in experiments repeated later by Priestley and Armstead, in which the leaves were immersed in water.

$$
\text { NO. } 283 \text { I, VOL. I I } 3 \text { ] }
$$


Dixon has driven water back along the vascular tracts in the leaf by placing the blade under an external gas-pressure higher than the osmotic pressure in the leaf-cells. Here again, however, without further evidence of the distribution of the pressure gradient, it would seem natural to assume that the water was driven merely out of the living cells, which surround the vascular cylinder in an airtight sheath, not from the cells of the leaf, external to this layer. Dixon also directs attention to the evidence for the movement of hormones in the xylem as witness that organic substances are distributed by their tissue (see NATURE, Dec. I, I923, p. 799, "The Nerves of Plants ").

On the other hand, quite independently, in America, Mr. Otis F. Curtis, in two papers printed in the American Journal of Botany (vol. 7, 1920, and vol. 10, 1923), has been describing experiments which have convinced him that, although carbohydrates may be present in the xylem sap, the xylem is not responsible for their transport. Thus if a healthy shoot is ringed through the phloem, so long as there are leaves above the ring a fair amount of growth is made; but if the leaves above the ring are removed, practically no growth follows, unless even a narrow strip of phloem be left, when growth is very considerable. These experiments seem to prove too much. They were performed with the sugar maple amongst other plants, and in the bleeding season. The conclusion here would seem to be that with plenty of sugar in the sap of the xylem vessels, the sugar must certainly pass above the ring if the young xylem is undamaged, but that sugar alone is not sufficient for growth, and something else is either required to be received (or removed) in small quantity, so that a small strip of phloem suffices for the purpose. Curtis's experiments on the failure of starch to disappear from a region of the stem isolated between two rings through the phloem are, however, very striking, and seem to provide very strong evidence that such carbohydrates are transported by the phloem. In his later paper, by analysis of the shoots above a ring and by observations of symptoms of nitrogen starvation even when the roots are fully supplied with nitrate, he shows that there is considerable evidence that nitrogen and the inorganic constituents found in the ash of plants pass such a ring with difficulty.

The phenomenon of leaf-roll in the potato may ultimately throw light upon this problem. Murphy has shown clearly (Proc. of the Royal Dublin Soc., vol. I 7 , No. 20, 1923) that the rolling of the leaves is a direct consequence of the excess accumulation of assimilates within them, and it would certainly seem significant that this symptom of the "virus" disease known as leaf-roll is constantly associated with a disorganisation of the phloem. The causal connexion of the two phenomena is, however, still in doubt, Quanjer arguing that the assimilates accumulate on account of the disorganisation of the phloem, Murphy that the phloem disorganises for lack of its proper work, the removal of the assimilates which fail to reach it from the leaf-blade.

\section{$\mathrm{Ob}$ ituary.}

\section{Mr. W. M. PyBus.}

MR. WILLIAM MARK PYBUS, who died on January 4, was born on April 10, x851. He was an eminent lawyer in Newcastle-on-Tyne, and he devoted his spare time to natural history, mainly to ornithology. His collection of eggs is well known to ornithologists and is in many respects unique. It numbers about 40,000, and is perhaps the most complete in existence. The many duplicate specimens of the same species were selected with great care to illustrate variation with especial reference to the eggs of the guillemot and the razor bill, and variations also with regard to locality. In all cases a complete record is given of the time and the place of collection, and the specimens are in a perfect state of preservation. In one case, at least, the collection includes an interesting clutch resulting from a cross between the black cock and the common fowl, and it illustrates the effects grouped under the term "hybrid oology."

Mr. Pybus made many journeys in the nesting season to different places in the northern counties, and later to St. Kilda, the Scilly Isles, the Orkneys and Shetland, and the journeys were usually followed by chatty ornithological papers from his pen. In rgor he was elected president of the Tyneside Naturalists' Field Club, and his presidential address printed in the Transactions of the Club contained many important ornithological observations. He contributed also an interesting and suggestive paper on the destruction of sand eels by their many enemies, and especially by the heat of the sand between tide marks in summer, from observations made on the Northumberland coast. An account of this work will be found in the Report of the Dove Marine Laboratory for r91 2.

A. M.
WE regret to announce the death, on January 17 , of Mr. Philip Buckle, lecturer in agricultural zoology in the University of Durham. Mr. Buckle was only twenty-seven years of age, and had already published several papers of interest and importance. He was joint author with Mr. Wardle of the recently published work, "The Principles of Insect Control."

WE regret to announce the following deaths :

Prof. E. Emrys-Roberts, professor of pathology and bacteriology in the Welsh National School of Medicine (University of Wales), Cardiff, also known for his antiquarian interests, on January I5, aged forty-five.

Gustaf Eneström, of Stockholm, founder and for eighteen years editor of Bibliotheca Mathematica and well known for his work on the history of mathematics, aged seventy-one.

Prof. Marcus Hartog, emeritus professor of zoology at University College, Cork, on January $2 \mathrm{r}$.

Sir Archibald Reid, president of the War Office X-Ray Committee, I9I4-I9, and joint secretary of the Radiology Section of the International Congress of Medicine, on January $1_{5}$, aged fifty-two.

Prof. S. P. Sadtler, formerly professor of organic and industrial chemistry in the University of Pennsylvania and a past-president of the American Institute of Chemical Engineers, on December I4, aged seventy-six.

Prof. J. M. Stillman, emeritus professor of chemistry at Stanford University, to which institution he was appointed in I89I, on December 13 , aged seventy-one.

Prof. R. R. Thompson, professor of oil mining in the University of Birmingham, on January 24, aged thirty-nine.

$$
\text { NO. } 283 \text { I, VOL. I I } 3 \text { ] }
$$

